\title{
Historia de México
}

\section{History of Mexico}

\author{
Von Wobeser, Gisela (coord.) (20io), Historia de MÉXico, \\ Fondo de Cultura Económica-Secretaría de Educación \\ Pública, MÉxico, 288 PP., ISBN: 978-607-I60-I73-5.
}

Para la conmemoración del Bicentenario de la Independencia el gobierno federal ha tenido a bien apoyar una serie de publicaciones de obras históricas, cuya finalidad es recordar las gestas históricas que han dado origen al México actual. El licenciado Felipe Calderón Hinojosa, presidente de los Estados Unidos Mexicanos, aseguró que éstas tienen como objetivo principal hacer un balance entre los logros alcanzados y los retos por cumplir, afirmó que la pluralidad cultural e ideológica que siempre ha caracterizado a México tiene su reflejo en el devenir histórico.

Esto no es nuevo, pues durante la época del Porfiriato, y en conmemoración del primer centenario de la guerra de Independencia, se mandaron elaborar historias de México: la más famosa México a través de los siglos, coordinada por Mariano Riva Palacio.

Ahora dos han sido las obras, a nivel general, que el presidente promovió, una titulada: Un viaje a través de la historia de México, de la pluma del maestro Luis González y González, impulsor de la microhistoria mexicana, libro que se ha distribuido de forma gratuita en cada casa a lo largo y ancho de la Republica Mexicana. Y la otra es la que ahora reseñamos, Historia de México, escrita por los miembros de la Academia Mexicana de la Historia, coordinados por su directora Gisela Von Wobeser, quien asegura en la introducción que resultó altamente satisfactorio colaborar con la Secretaría de Educación Publica y contribuir así a la celebración del Bicentenario del inicio del movimiento de Independencia y del Centenario del comienzo de la Revolución mexicana.

Este texto consta de 13 capítulos que llevan al lector paso a paso a través de la historia de México: está dirigida a todos los mexicanos, es una obra de divulgación que no pierde el rigor profesional, y donde cada uno de los autores muestra su punto de vista y su libertad de pensamiento. No intenta dar nuevos aportes, pero tampoco es una historia de bronce escrita para satisfacer al régimen, sino más bien en forma amena y sintética muestra el orgullo que debemos sentir todos los mexicanos al conocer nuestra historia.

El primer capítulo describe las regiones que integran México, las divide en cinco con la finalidad de que al conocerlas se comprendan las acciones que a través de la historia se han forjado en cada una de ellas. 
Resalta la importancia que tiene su orografía, fauna, flora, hidrografía, elementos que las caracterizan, y que unidos dan singularidad al gran mosaico cultural que es nuestro país, e incluso nos recuerda cómo en el ámbito popular a través de canciones y corridos se habla del entorno geográfico empezando por México, lindo y querido... y terminando con El caminante del Mayab. El único reclamo que los mexiquenses hacemos es que no se mencione Zacazonapan.

Llama la atención que al hacer mención a la diversidad de nombres que se han asentando en la geografía del país, hay uno que lo preside y lo domina todo: México. "De muchas maneras lo encontramos repetido en diversas latitudes y sentidos: Ciudad de México, Golfo de México, Imperio Mexicano, República Mexicana, Estados Unidos Mexicanos, Nuevo México, Valle de México, Mexicali (que significa México-California) y Estado de México" (p. 20).

Esta última entidad federativa se ubicada en lo que se denomina México central, y una buena parte está conurbada con el Distrito Federal, lo que le ha dado una fisonomía muy peculiar, y cuyas dimensiones aumentan en población y en necesidades urbanísticas.

Manuel Ceballos Ramírez, quien escribe sobre el espacio mexicano, logra hacer una buena síntesis del libro del doctor Bernardo García Martínez, Las regiones de México: breviario geográfico e histórico.

El segundo capítulo de la obra, "Orígenes y desarrollo de Mesoamérica”, escrito por el doctor Miguel León-Portilla, hace una síntesis muy inteligente del desarrollo de una civilización conocida como Mesoamérica y llega a compararla con otras civilizaciones importantes del mundo, como la de Egipto, Mesopotamia, el Valle del Indo, el de la cuenca del Amarillo en China, y la región andina. Todas ellas originales.

La civilización originaria se inicia con los olmecas, la cual se difundió hacia cinco áreas culturales: "las costas del golfo de México, la zona maya, la de Oaxaca, la del Altiplano central, y con menor intensidad hacia el occidente de México" (p. 49). De estas cinco áreas el autor hace un recorrido que comienza en el periodo Clásico, continúa en el Postclásico y llega a la etapa final en el desarrollo de Mesoamérica, que son los años comprendidos entre 1200 y 1521, con la llegada de los españoles se cerró la historia independiente de sus habitantes.

En forma amena nos relata la historia de los mexicas, menciona a sus señores o tlatoanis, las conquistas que realizaron para quedar como jefes de un gran imperio. Nos describe las esculturas que elaboran, sus pirámides y su cultura, hasta llegar a la víspera del encuentro con los españoles. Cierra este capítulo con un resumen inteligente sobre la herencia cultural de Mesoamérica, donde nos señala las lenguas y su influencia en el lenguaje actual de México, de la música, e instrumentos musicales como el tololoche, del baile conocido como mitote, de invenciones como 
la chinampa, los temascales, los apantles y otros. De los árboles y su aprovechamiento, de los animales, los frutos y la vida cotidiana, y para no alargar la lista nos muestra los rasgos culturales heredados del mundo indígena, como las formas de cortesía, el uso frecuente de diminutivos, el sentido comunitario, el apego a la familia, la sensibilidad artística; y algunas importantes formas de religiosidad, como el culto a nuestra Madre Guadalupe y a nuestro padre Jesús, esa realidad evoca a la prehispánica Ometeotl-Tonantzin.

José María Muriá escribe sobre la conquista de México, empieza analizando el efecto que tuvo el encuentro de dos mundos diferentes y explica el origen de la palabra indios, dado a sus pobladores al considerar que habían llegado a las Indias occidentales, asegura que ambos mundos se enriquecieron con sus aportaciones. Lo más interesante de este capítulo es que habla de los conquistadores, en plural, y de las zonas que cada uno de ellos dominó. No es el relato tradicional de Hernán Cortés y la conquista de Tenochtitlán con la ayuda de Jerónimo de Aguilar y de doña Marina, mejor conocida como la Malinche, que fueron realmente las voces de Cortés, sino que describe zona por zona las primeras fundaciones de ciudades, los asentamientos y la expansión entretejiendo las rencillas que se dieron entre los conquistadores.

Es sugestivo ver que fue un movimiento difícil, debido a que el grupo de conquistadores venía también de un mundo diverso y con muchos conflictos internos, nos habla del sureste mexicano, del occidente, del noreste, de Guatemala y Honduras. Sobre todo remarca lo conflictivo que fue conquistar Chiapas y Yucatán. Menciona la importancia de los primeros misioneros franciscanos, dominicos y agustinos, termina su interesante capítulo con la formación del gobierno y las nuevas conquistas de Nueva Galicia y Yucatán.

A manera de conclusión podemos decir que es un estudio preciso y claro de la conquista de México, en un periodo largo que abarcó de 1519 hasta 1545 , durante este tiempo la población indígena se redujo más de la mitad y continuó disminuyendo durante los primeros años de la Colonia hasta quedar aproximadamente $5 \%$ de la población que existía antes de la Conquista. Cabe señalar que la lucha más sangrienta entre españoles e indios no fue a aquella del primer encuentro, más bien la que se dio cuando éstos se insurreccionaban. Lo cierto es que los españoles fueron recibidos en paz, pero el saqueo, la esclavitud y otras tropelías llevaron a constantes enfrentamientos, el resultado fue la baja sustancial para ambos contendientes y al final los conquistadores se establecieron en el territorio, que posteriormente nombrarían Nueva Espańa, procuraron organizarse y vivir lo más parecido posible a como lo hacían en su tierra.

La etapa que conocemos como el Virreinato de la Nueva España está dividida en tres apartados, escritos por Gisela Von Wobeser, quien coor- 
dinó la obra y es la directora de la Academia Mexicana de la Historia, Jorge Alberto Manrique y Ernesto de la Torre Villar, quienes también aportaron su conocimiento sobre la Nueva España. En el primero trata el desarrollo en el siglo Xvi de un país mestizo, multiétnico y multicultural, con un potencial extraordinario y que se llamó Nueva España, resalta el predominio de las estructuras indígenas sobre los demás elementos culturales, la prevalencia de las lenguas indígenas pero que la lengua franca era el náhuatl, cómo poco a poco se incorporara la lengua castellana, el sistema jurídico español, la religión católica, la escritura occidental, la economía de mercado, el pensamiento y las costumbres hispanas y la tecnología europea, entre otros elementos. Marca tres causas de la hispanización: la imposición de la cultura del vencedor sobre los vencidos y la pronta aculturación de los indígenas, el segundo factor fue la caída demográfica de la población nativa, y el tercero, la reproducción desmesurada de ganado traído de Europa y la inserción de la Nueva Espańa en el circuito económico.

Es interesante ver la reordenación y reestructuración del espacio a través del establecimiento de pueblos congregados, donde la vida cotidiana era determinada por el calendario litúrgico-religioso y la fundación de dos repúblicas: una de españoles y otra de indígenas, ambas con distinto grado de autonomía. Pronto los indígenas se convirtieron en súbditos de la Corona española, la nobleza indígena paulatinamente desapareció, o se integró a la sociedad española y después se mestizó. Por su parte, los indígenas incorporaron a la dieta española elementos culinarios nativos, particularmente el jitomate y el chocolate. Otra rama productiva que floreció en el siglo Xvi fue la minería, el metal más codiciado era el oro, pero en realidad lo que más se explotó fue la plata, este auge minero se dio entre 1531 y 1552, convirtiéndose en el principal motor de la economía. También se suministraron artículos de exportación, como la grana cochinilla y la seda de oriente que llegaba a través del galeón de Manila.

En el aspecto ideológico la piedra angular fue la evangelización, utopía que los españoles supieron buscar a través de las órdenes mendicantes. La construcción de conventos cuyos claustros se destinaron principalmente a actividades comunitarias de los frailes y fueron importantes centros de intercambio cultural entre indios y españoles, pues mientras los primeros eran hispanizados, los segundos aprendieron las lenguas indígenas; aquí cabe resaltar el colegio de indios de San José de los Naturales, anexo al convento de San Francisco en la ciudad de México y el Colegio de Santa Cruz de Tlatelolco, centro educativo de excelencia, donde el franciscano Bernardino de Sahagún escribió la Historia general de las cosas de la Nueva España. En 1572, al arribar la Compañía de Jesús, en sus colegios se intensifica la labor educativa para los criollos. 
Manrique escribe sobre el siglo XviI, etapa de la consolación de Nueva España, describe la vida cotidiana, la política y el dominio de la Iglesia. Hace un bosquejo interesante de los ayuntamientos, los juzgados de indios, del Virreinato, de la armada de Barlovento y de las relaciones entre Iglesia y Estado. Analiza la división territorial de la Iglesia y remarcan las zonas seculares y regulares, muestra al Santo Oficio de la Inquisición como el instrumento de control de la Iglesia y asegura que el mayor daño que ocasionó fue la inhibición de la libre expresión.

En la vida económica describe la agricultura, la ganadería, el comercio y la minería, y asegura que era un negocio lucrativo pero muy riesgoso, y que junto con el Perú, la Nueva España fue el centro minero más importante del Imperio español. Se solaza con una descripción pormenorizada de la educación y la ciencia en los colegios y la universidad. Describe la llegada de la imprenta y la importancia que ésta tuvo para difundir la ciencia, y asegura que el primer libro que se imprimió fue la biografía de Catalina de San Juan, escrito por Alonso Ramos en tres tomos.

La vida cotidiana nos la presenta a través de la vestimenta de hombres y mujeres, afirma que surge el rebozo como prenda importante en la mujer y el gabán para el hombre. Describe la sociedad dividida en clases y éstas, a su vez, separadas en barrios. Menciona los mercados importantes en la ciudad de México y los hospitales que atendieron la salud de los novohispanos, incursiona en el arte y la cultura, resalta las catedrales de Puebla, México y Oaxaca. Al igual que algunas iglesias como Santo Domingo de Puebla y San Agustín, donde el arte barroco cobró mucha importancia, en la pintura nos da una verdadera clase a través de las obras y sus autores.

Menciona la importancia de la música profana y religiosa que se cultivó en las ciudades, villas de españoles y en los pueblos indígenas, asegura que se introdujeron instrumentos musicales indígenas junto con los europeos, y en las letras resalta a Juan Ruiz de Alarcón, sor Juana Inés de la Cruz y al científico y escritor Carlos de Sigüenza y Góngora, contándonos su biografía.

Concluye que el siglo XviI empezó con dos grandes crisis: la de población y la de minería. Hubo dificultades entre las autoridades y despojos de tierras, pero para mediados de este siglo se consolidó la Nueva España en forma brillante en la producción, el comercio, las instituciones y la cultura. "Nueva Espańa ya era una sociedad nueva con sus propias necesidades y creaciones" (p. 136).

Don Ernesto de la Torre Villar nos habla del Virreinato de la Nueva España en el siglo xviII, asegura que fue una época de extraordinaria recuperación de la población y un mestizaje dinámico, pero había un gran desigualdad entre la población: en cuanto a su origen, economía, organi- 
zación política y cultural. Nos lleva a conocer a las autoridades civiles y eclesiásticas a través de cada uno de los virreyes de ese siglo, y finalmente expone la expulsión de los jesuitas, producto de las Reformas Borbónicas y del movimiento de la Ilustración.

Acerca de la independencia, 1808-1821, la doctora Virginia Guedea escribe sobre la causa por la que Nueva España se convierte en el México independiente a través de un proceso histórico más amplio. Sostiene que la formación del Estado nacional mexicano abarca buena parte del siglo XIX y es, por otra parte, lo que conocemos como la revolución hispánica, que llevó a España a convertirse en un Estado moderno y provocó la desintegración de su Imperio. No sólo Nueva España se independizó de la metrópoli, sino que también lo hicieron casi todos los territorios españoles de América.

La insurgencia recorrió un camino muy sinuoso y se desarrolló en varios territorios de la República Mexicana, sobre todo en los espacios que conocemos como el México central; hubo reivindicaciones políticas y sociales; del grueso de las filas insurgentes, campesinos y trabajadores fueron escuchados por primera vez, también hablaron los marginados de las ciudades que solicitaban la restitución de la tierra o del agua; esto dio como resultado una insurrección netamente popular. Fue un movimiento de violencia, desorden y ruptura en todos los órdenes, además de anárquico. La autora resalta cómo la guerra provocó el deterioro de la economía novohispana, al detener el envío de dinero a la Península y las redes comerciales. Por otra parte, la contrainsurgencia intentó sofocar las manifestaciones utilizando como principal recurso a la religión, pues el alto clero lanzó contra los insurgentes anatemas y excomuniones. Otro problema fue la dificultad para establecer relaciones con el exterior y conseguir auxilio de otros países.

El capítulo cierra con el pacto de las tres garantías que celebraron, por un lado, el realista Agustín de Iturbide, enviado a combatir a los insurgentes en el sur; y por el otro, el insurgente Vicente Guerrero, al proclamar la Independencia en un documento conocido como Plan de Iguala, donde se establecía una monarquía moderada como forma de gobierno. No recogió muchas de las reivindicaciones que había sostenido la insurgencia, dejaba intacto al clero, a los ramos del Estado y a los empleados públicos, lo mismo que la administración de la justicia. No obstante, sí retomó ese viejo anhelo autonomista de crear una junta de gobierno. El acta de Independencia del Impero mexicano se fechó el 28 de septiembre de 1821. Llama la atención que ningún antiguo insurgente la firmó y sí lo hicieron antiguos autonomistas y desafectos al régimen colonial.

El país dio comienzo a su vida independiente sin haber resuelto los conflictos de interés que se daban entre los distintos grupos, lo que llevaría a un largo camino para la consolidación del Estado nacional mexicano. 
La doctora Josefina Zoraida Vázquez, en un esfuerzo intelectual, nos habla sobre el establecimiento del México independiente de 1821 hasta 1848. Esta etapa se caracterizó por diferentes eventos políticos, asonadas, guerras extranjeras e inestabilidad constante. Lograda la Independencia se anexó Guatemala (que comprendía hasta Costa Rica) a la nueva nación, el territorio llegó a tener cuatro millones y medio de kilómetros cuadrados, contaba con grandes riquezas pero con una población escasa, aproximadamente seis y medio millones, distribuida de manera desigual. Surge un país heterogéneo con grandes contrastes sociales y raciales.

Se estableció un gobierno imperial en 1821, encabezado por Agustín de Iturbide. El malestar de los habitantes proliferó en las provincias, lo que aprovechó Antonio López de Santana para pronunciarse contra el gobierno el 2 de diciembre de 1822. La consecuencia fue que Iturbide abdicó la corona el 22 de marzo de 1823 y se exilió. El Congreso redactó un acta constitutiva y la Constitución en 1824, estableciendo una república representativa, popular y federal.

Guadalupe Victoria, primer presidente de México, empezó a trabajar con los escasos recursos otorgados. Se enfrentó a la industria mexicana que estaba en franca decadencia, los textiles ingleses la dañaban aún más. El cobro de impuestos continuaba sin regularizarse y el contrabando se había generalizado. También había falta de comunicación, mucha inseguridad, no existía una moneda y menos un banco. Además, empezaron a fundarse logias masónicas como la yorquina y la escocesa, una pugnaba por el federalismo y la otra por el centralismo. A esto se unió la conspiración del padre Arenas, que dio como consecuencia la expulsión de los españoles. Con trabajos termina su periodo y empieza una serie de disturbios por obtener la silla presidencial, donde los actores son Nicolás Bravo, Vicente Guerrero, Mier y Terán, Santa Anna, Valentín Gómez Farías, y atrás de ellos, Lucas Alamán, todos con muy buenas intenciones pero enfrentados entre sí. En esa época tuvo lugar la colonización e independencia de Texas.

La autora describe la vida cotidiana, donde resalta el contraste de la población mexicana, que se caracteriza por diferencias impresionantes: $10 \%$ de la población contaba con riquezas extraordinarias; $68 \%$ vivía con 50 pesos anuales, $22 \%$ lo hacía con entre 50 y 300 pesos; y los extranjeros recién llegados acapararon el comercio, la industria y la minería. Pero los más favorecidos para enriquecerse fueron los usureros. La burocracia fue víctima de la falta de presupuesto y algunos profesionistas prosperaron (abogados y médicos), el resto de la población: rancheros, peones, trabajadores de minas, obreros, artesanos, sirvientes, vendedores, aguadores, eloteros, léperos y otros apenas sobrevivieron. En general la sociedad mantuvo los usos y las costumbres virreinales, aunque lentamente se fue secularizando. 
La convicción de que la educación era el camino al progreso llevó a un grupo de notables a fundar la Compañía Lancasteriana; las universidades de México y Guadalajara se convirtieron en institutos literarios donde se formaron los profesionistas republicanos. El prestigioso Colegio de Minería decayó y en 1838 se fundó la Academia de Medicina. La Academia de San Juan de Letrán y el Ateneo Mexicano fueron los vehículos de difusión. Las publicaciones de mayor circulación fueron lo periódicos, folletos y hojas volantes de carácter político.

En cambio, la economía se mantuvo estancada a pesar de que a mediados de siglo la industria textil fue impulsada por Lucas Alamán y Antuñano. La minería atrajo a británicos y alemanes, pero mucho del producto salió de contrabando. La agricultura tardó en recuperarse, se intentó hacer reformas agrarias en varios estados. La inseguridad de los caminos, las malas comunicaciones, el alto costo de la arriería y la falta de un banco y de moneda flexible obstaculizaron el comercio. Los grandes proyectos para construir ferrocarriles fracasaron, los grandes barcos eran todos extranjeros. A pesar de ello, se abrieron rutas comerciales hacia el norte: Santa Fe, Chihuahua y Texas.

Cabe destacar lo atinado del capítulo de la doctora Vázquez, que en pocas cuartillas nos muestra un panorama histórico de un México convulsionado, lleno de problemas e intentos por solucionarlos, con muchas buenas intenciones, pero con una base de caudillos y caciques que obstaculizaron el desarrollo del país.

Andrés Lira estudia el periodo 1853-1887, al que denomina "La consolidación nacional”, lo más notable es la Constitución liberal de 1857, que estaría vigente hasta bien entrado el siglo $\mathrm{xx}$, y asegura que de los cinco presidentes que basaron su autoridad en ella, cuatro terminaron el periodo para el que fueron electos y de éstos, dos, Benito Juárez y Porfirio Díaz, permanecieron en la silla presidencial por largo tiempo alegando necesidades de orden político-institucional o reformas constitucionales.

La dictadura de orden constitucional encabezada por Antonio López de Santa Anna fue la que siguió a la guerra con Estados Unidos, en la que México perdió más de la mitad de su territorio, misma que cayó con el Plan de Ayutla liderado por los liberales que encabezaba el general Juan Álvarez. El Congreso Constituyente se reunió en febrero de 1856 y concluyó su labor un año después, cuando aprobó la Constitución Federal de 1857, en este ínterin, se promulgaron las Leyes de Reforma. Éstas provocaron una guerra civil al ser rechazadas por el pueblo, azuzado sobre todo por la Iglesia. El presidente Comonfort la promulgó y luego renunció, Juárez quedó como presidente ya que era el líder de la Suprema Corte de Justicia, a lo que se opuso el general Zuloaga, representante de los conservadores. 
Esta guerra duró tres años y fue de carácter civil, pues dividió a la sociedad en el seno mismo de las familias. El segundo Imperio promovido por los conservadores y encabezado por Maximiliano de Habsburgo no tuvo éxito. El presidente Juárez entró triunfante a la ciudad de México el 15 de julio de 1867, convocó a elecciones de los poderes de la unión en agosto de ese año, y fue electo para el periodo 1868-1871. Al terminar su gobierno se volvió a convocar y junto con él surgen dos candidatos a la silla presidencial: Sebastián Lerdo de Tejada, veracruzano, y Porfirio Díaz, oaxaqueño. Luego de una reñida y dudosa elección gana Juárez pero muere al año siguiente, Lerdo se hace cargo de la presidencia.

El gobierno de Lerdo, que debía concluir en 1875, logró importantes avances en la reforma a la Constitución en 1873, elevó a rango constitucional las Leyes de Reforma y promulgó el carácter laico del régimen con la separación entre Iglesia y Estado, también se creó el Senado y el Congreso pasó a ser un órgano bicameral, logró el reestablecimiento de las relaciones con Gran Bretaña y atrajo capital inglés para concluir el ferrocarril México-Veracruz. Todo lleva a ver que Lerdo fue un avezado político, compañero y consejero de Juárez en los días difíciles de la guerra y contra la intervención. Su error fue intentar reelegirse para el periodo siguiente, donde sus contendientes fueron José María Iglesias y Porfirio Díaz, este último se levantó en Tuxtepec proclamando la "No reelección" al declarar a Lerdo como presidente.

Termina este capítulo con el liberalismo conservador 1876-1889, menciona los logros importantes que dieron al país tranquilidad, crecimiento económico y estabilidad, entre otros: el campo empezó a modernizarse con la expansión del ferrocarril, al atender la demanda de granos y de otros productos de lugares lejanos; las compañías mineras aumentaron sus actividades, y para 1888 había una red ferroviaria de 5,500 km que unía las ciudades y lugares del interior con la capital de la República -e incluso el Istmo de Tehuantepec-, y con Estados Unidos a través del Paso del Norte.

Javier Garcíadiego escribe sobre el Porfiriato de 1876 a 1911, asegura que este periodo abarcó el último cuarto del siglo xix y el primer decenio del xx. Asevera que ningún otro periodo de la historia de México se identifica con el nombre de su gobernante, y para empezar nos da una breve semblanza de la biografía de Díaz. Divide este capítulo en tres etapas.

La primera es el ascenso y consolidación, entre los años 1876 y 1877 , donde se controlan cabalmente todas las instituciones e instancias políticas del país. Porfirio Díaz rápidamente se convirtió en el líder del grupo liberal en los ámbitos nacional e internacional con un proyecto que incluyó continuidades pero también cambios. Se esforzó por imponer la paz en el país, así fuera de manera forzada, y buscó el orden y el progreso, que eran sus objetivos principales. 
La segunda etapa empezó en el cuatrienio de 1884 a 1888, continuó controlando a los caudillos y caciques, y aquellos que no aceptaron disciplinarse fueron combatidos. Saneó la hacienda pública, prosiguió con la construcción de vías férreas y el establecimiento de instituciones bancarias. Lo más sobresaliente fueron las inversiones europeas y México empezó a exportar productos agrícolas, así como de minería industrial, especialmente cobre. Una característica de estos años fue la tolerancia concedida a los asuntos religiosos.

Empezó su lema de "poca política y mucha administración", en el periodo de auge contó con un equipo de asesores conocidos como Los Científicos, que decían ser liberales moderados. En cuanto a la economía, este grupo propuso la eliminación de las alcabalas; en política, que el régimen tuviera como forma de gobierno la dictadura, que consideraban benéfica. En materia sociocultural, ampliar el sistema de educación pública y que ésta fuera científica, y por último recomendó que no se escindiera la sociedad mexicana por causas religiosas. El resultado fue la estabilidad política y el crecimiento económico.

La tercera y última etapa del Porfiriato abarcó el primer decenio del siglo xx. La decadencia fue total y hubo crisis en casi todos los ámbitos de la vida nacional. La sociedad pedía un cambio y lo único que en política se les ocurrió fue restaurar la vicepresidencia que resultó fatal, surgieron críticas abiertas a Los Científicos. Vendrían las represiones a los obreros en Cananea y Río Blanco, se tuvo una severa crisis económica y Díaz anunció en una entrevista con James Creelman que no se reelegiría. Empezaron a surgir grupos que aspiraban llegar a la silla presidencial, como los reyistas, antirreeleccionistas y otros. En ese entonces entró en crisis la política exterior.

Todos estos problemas que enfrentó el régimen de Díaz se hicieron patentes con los grupos opositores e incluso con los jerarcas de la Iglesia, lo que resultó en unas elecciones viciadas donde el contendiente principal fue Francisco I. Madero, quien logró que Díaz, aun cuando se le consideró triunfador, renunciara y abandonara el país. El capítulo proporciona una idea clara de esta etapa de la historia de México, que ha sido vilipendiada, censurada y reprobada por la historia oficial instaurada en los regímenes posteriores.

Los años revolucionarios (1910-1934) fueron el objeto de estudio de Álvaro Matute, quien afirma que en un principio el Plan de San Luis y Madero fueron minimizados por la opinión pública. Sin embargo, mes a mes aumentaron los levantamientos, principalmente en los estados del norte del país. Muchos de ellos eran de trabajadores del campo, de los bosques y de las minas, por lo que eran hábiles en el manejo de las armas y las carabinas. Así, Porfirio Díaz renunció a la presidencia y se realizaron nuevas elecciones, que ganó Francisco I. Madero. Cabe aclarar que en 
algunos estados de la República la actividad revolucionaria fue intensa, pero en otros paso inadvertida.

Pronto surgieron otros movimientos independientes, como el de Emiliano Zapata en el estado de Morelos, en el norte Ricardo Flores Magón y Pascual Orozco. Algunos amigos de Don Porfirio se alzaron, como Bernardo Reyes y su sobrino Félix Díaz en el estado de Veracruz, todo desembocó en lo que conocemos como la Decena Trágica, donde fueron fusilados Francisco I. Madero y José María Pino Suárez, por órdenes de Victoriano Huerta.

Huerta usurpó el poder pero no duró mucho en él, exacerbó a los revolucionarios que estaban divididos. Venustiano Carranza organizó un ejército que se llamó constitucionalista y expidió el Plan de Guadalupe. Por su parte, Emiliano Zapata siguió con su lucha, al igual que Francisco Villa, antiguo maderista, y un grupo de sonorenses que habían combatido a Orozco, entre los cuales destacaba Álvaro Obregón, se sumaron a Carranza. La Revolución comenzó a escindirse a partir del reparto de tierras y hubo necesidad de instalar una convención en Aguascalientes, quedando divididos en dos fuerzas: por un lado Carranza con Obregón y por el otro Villa y Zapata.

Mientras entablaban los combates ideológicos y los armados, la población sufría hambre y vivía con zozobra. Hubo mucha inseguridad en el campo y las grandes ciudades recibieron migrantes, la vida seguía su curso normal hasta donde era posible. Ante este panorama se dio a conocer la Constitución Política de los Estados Unidos Mexicanos de 1917, donde sobresalieron las reformas radicales en lo concerniente a que la educación fue obligatoria, laica y gratuita; en el aspecto agrario se hablaba del subsuelo como propiedad de la nación; en el terreno laboral se establecieron salarios mínimos y jornadas máximas; en lo que tocaba a la religión se marcó la separación entre la Iglesia y el Estado, entre otras. Con la Constitución se cerraba al menos en el terreno legal un capítulo de la Revolución, aunque la realidad social y militar expresara lo contrario.

El único enemigo del gobierno de Carranza fue Emiliano Zapata, que fue asesinado en 1919. Ese mismo año empezaron a aparecer una serie de caudillos, como Álvaro Obregón, Plutarco Elías Calles, Adolfo de la Huerta, José Vasconcelos y otros, que terminaron por organizar el asesinato de Carranza. Entonces Obregón subió al poder.

Este gobierno se caracterizó por pacificar el país, construir vías férreas y carreteras, en el terreno educativo se dieron grandes avances, al final de él se logró el reconocimiento de México por parte del gobierno estadounidense.

El poder pasó a manos de Calles, quien con su radicalismo provocó una guerra contra la Iglesia, conocida como la Cristiada, que se prolongó durante tres años. El secretario de guerra, Joaquín Amaro, coordinó las 
acciones para enfrentar a los cristeros; conflicto que terminó en 1929 con los arreglos que pusieron fin a la guerra.

En términos de su gobierno, Plutarco Elías Calles continuó con las obras de infraestructura, la fundación del Banco de México y mantuvo buenas relaciones con Estados Unidos, a pesar del problema con el petróleo. Álvaro Obregón quiso tomar el poder otra vez, pero fue asesinado por José de León Toral. Tras este hecho, el presidente Calles, en su informe el $1^{\circ}$ de septiembre de 1928, aseguró que había concluido la era de los caudillos y comenzaba la de las instituciones. Formó un partido político con estas ideas, denominado Partido Nacional Revolucionario (PNR), encargado de realizar las elecciones.

No fue fácil transitar a la democracia, pues Calles se transformó en el Jefe Máximo de la Revolución, y al dejar la presidencia a cargo de Pascual Ortiz Rubio y tratar de manejarlo, éste presentó su renuncia y subió al poder Abelardo L. Rodríguez, estableciendo una reforma constitucional conocida como Plan Sexenal, así la presidencia cambio de cuatro a seis años. El ambiente político estuvo lleno de enfrentamientos ideológicos, el más notable se dio entre el socialista Vicente Lombardo Toledano y el idealista Antonio Caso, en torno a la orientación ideológica de la Universidad Nacional, el rector Manuel Gómez Morín medió y se logró la libertad de cátedra.

Jean Meyer continúa analizando México entre 1934 y 1988, asegura que después de 24 años de violencia, casi ininterrumpida, vino un sexenio presidido por el general Lázaro Cárdenas, quien puso orden e hizo reformas. Tuvo que expulsar del país a Calles, empezó a hacer repartos agrarios, nacionalizó la producción petrolera, abrió bancos para prestar dinero a los campesinos, y se apoyó la enseñanza técnica con la fundación del Instituto Politécnico Nacional.

El mayor cambio político fue la conversión del PNR al Partido de la Revolución Mexicana (PRM) en 1938. Éste fue el primer partido político en que participaron distintos sectores de la sociedad: el obrero, campesino, popular y militar. Como una respuesta a este partido, surgió un grupo de derecha, opositores, que creó el Partido de Acción Nacional (PAN) en 1939. Así dejó Cárdenas el poder en manos de Manuel Ávila Camacho, último militar que llegó a la presidencia, cuyo propósito fue la unidad nacional y a él le tocó enfrentar la segunda Guerra Mundial, que en cierto modo benefició a México, pues logró la tan anhelada unidad nacional, y propició una época de cooperación y entendimiento con Estados Unidos como no se había tenido antes. En el terreno social se realizó una exitosa campaña de alfabetización y se fundó en 1943 el Instituto Mexicano del Seguro Social (IMss).

Se inicia la época de los licenciados que sustituyen a los militares, el PRM se transformó en 1946 en el Partido Revolucionario Institucional 
(PRI), cuyo lema fue: "Democracia y justicia social". Con este partido llegó a la presidencia Miguel Alemán, quien estimuló el crecimiento de las industrias y de las ciudades; se empezaron a recibir inversiones extranjeras y se favoreció el desarrollo de la agricultura moderna; el turismo por primera vez fue una actividad económica importante y Acapulco fue la punta de lanza. Cuando Alemán dejó la presidencia en 1952, el país había cambiado de manera radical.

La población creció y empezaron a aparecer los nuevos ricos, así llegó al poder Adolfo Ruíz Cortines, quien gobernó entre 1952 y 1958, encontrándose con las arcas públicas vacías y una inflación desatada. Tuvo que restaurar la unidad de la familia revolucionaria y le tocó devaluar el peso a buen tiempo. Dejó el poder al joven mexiquense Adolfo López Mateos, que gobernó de 1958 a 1964, y a quien le tocó enfrentar una intensa agitación sindical y transitar entre Fidel Castro y Cuba y el imperialismo yanqui; en 1960 nacionalizó la energía eléctrica. En suma, esos años fueron buenos para la economía y el pueblo se quedó con el recuerdo de un presidente amable y sonriente.

El sexenio siguiente fue presidido por Gustavo Díaz Ordaz, quien manifestó una energía extrema, bajo su mandato la sangre corrió en Tlatelolco el 2 de octubre y esa sangre no se ha olvidado. La sociedad estaba en profundas transformaciones y el sistema político no llevaba a cabo los cambios necesarios, pasaba de ser de un país rural a un país urbano. En 1968 se organizaron los Juegos Olímpicos y continuó el crecimiento económico, a la prosperidad se le llamó desarrollo estabilizador, e intentaba favorecer a las clases medias urbanas.

Entre la década de 1970 y 1980 el crecimiento económico se mantuvo muy alto, pero el país había empezado a endeudarse y se debilitó la economía, que llevó a una devaluación muy fuerte en el gobierno de Luis Echeverría: el dólar pasó de 12.50 pesos a 29. Este presidente tuvo grandes ambiciones, se caracterizó por ser populista y de nuevo le tocó enfrentar a los estudiantes el 10 de junio de 1971, consecuencia del 2 de octubre de 1968. Aparecieron los movimientos guerrilleros en varios puntos del país, al término de su periodo de gobierno, México quedó con una enorme deuda.

Cuando en 1976 José López Portillo llegó a la presidencia, los ciudadanos tuvieron esperanzas de un cambio. Se habló de una bonanza petrolera sobre todo en Campeche y Tabasco, la economía volvió a crecer muy rápido, el gobierno no supo administrar bien ese dinero, el endeudamiento continuó, aunado a la corrupción. El presidente aprovechó la bonanza para lanzar una reforma política, donde se pusiera fin al monopolio absoluto del PRI. Sin embargo todo cambió en 1981, cuando el precio mundial del petróleo empezó a bajar, en febrero del siguiente año el gobierno aco- 
rralado tuvo que devaluar a 70 pesos por dólar, y en septiembre decidió nacionalizar la banca. Terminó su gobierno siendo muy impopular.

En 1982 México ya era una sociedad moderna y urbana, se puso en marcha la primera red de estaciones transmisoras para enviar la señal de televisión a todo el país, y Miguel de la Madrid gobernó hasta 1988. El país entró en una crisis global y larga que también golpeó a varios países de América Latina y Europa. Le tocó afrontar el temblor más terrible que haya sufrido México en el siglo xx, sobre todo en la ciudad de México y en los estados de Michoacán, Jalisco y Guerrero. Para 1986 se hizo una nueva reforma electoral donde participaron diversos partidos en las elecciones presidenciales de 1988.

Este capítulo refleja el gran conocimiento que el doctor Meyer tiene sobre este periodo de la historia de México: da al lector en un pequeño esbozo los hechos más sobresalientes que dieron lugar al México de hoy.

Enrique Krauze estudia el México contemporáneo (1988-2008). Asegura que en 1989 ocurrieron dos milagros globales: la caída del Muro de Berlín y la adopción generalizada de la democracia en América Latina. La política liberalizadora que el nuevo presidente, Carlos Salinas de Gortari, trajo a México adoptó en términos económicos su equivalente en la arena política. Así, el PAN obtuvo en 1989 la primera gubernatura de su historia (Baja California) y tres años después también triunfó en Chihuahua. La razón tácita era el resultado de una elección turbia en 1988, donde el gobierno estaba dispuesto a tener alternancia con la derecha, pero no con la izquierda. Según versiones serias, ese año triunfó el candidato presidencial de la izquierda, Cuauhtémoc Cárdenas, pero el aparato político del gobierno priista no lo reconoció. Así se entabló una lucha entre priistas e izquierdistas que formaron el Partido de la Revolución Democrática (PRD).

El error más costoso del periodo de Carlos Salinas de Gortari fue la falta de una auténtica reforma política. Su gestión, marcada por su fuerte liderazgo, fue un claroscuro. Durante su gobierno estalló la rebelión neozapatista acaudillada por el subcomandante Marcos; se firmó un tratado de libre comercio; y le tocaron episodios traumáticos, como el asesinato de Luis Donaldo Colosio, candidato priista a la presidencia de México, de José Francisco Ruiz Massieu y el cardenal Posadas Ocampo. Con todos estos cambios llegó a la presidencia Ernesto Zedillo (19942000), quien inició su gestión con una crisis económica; dio total independencia al Instituto Federal Electoral, lo que condujo a que el gobierno del Distrito Federal pasara a manos del PRD, encabezado por Cuauhtémoc Cárdenas; en el año 2000 el PRI perdió las elecciones presidenciales, y se convirtió en realidad la alternancia política con el PAN y su candidato Vicente Fox. 
Fox resultó mucho mejor candidato que presidente, según asegura Krauze. Hay que reconocer que su gobierno tuvo un manejo responsable de las finanzas públicas, un respeto al orden democrático y la introducción de reformas como la Ley de Transparencia, así dejó la presidencia a Felipe Calderón, quien dio inicio al segundo periodo presidencial del PAN, luego de unas discutidas elecciones en el 2006 y una toma de posesión tensa.

Felipe Calderón, de estilo discreto, serio y ejecutivo, comenzó una lucha frontal contra el crimen organizado. En el ámbito de la modernización económica, el régimen ha entablado una relación funcional con el Congreso, que le ha permitido que se aprueben leyes importantes, como la de pensiones o la reforma energética. Mucho falta para modernizar cabalmente al país, aunque sigue dependiendo económicamente de Estados Unidos, las finanzas públicas se han saneado y hay reservas financieras.

Krauze dedica apartados interesantes al Tratado de Libre Comercio (TLC) y a la reforma del ejido, así como a la rebelión zapatista. Sobre todo asegura que la migración hacia Estados Unidos ha crecido en forma alarmante y el número de mexicanos que se fueron a vivir allá entre 1990 y 2000, alcanzó casi los cinco millones. Así, la cultura mexicana está presente en Estados Unidos desde la comida hasta la música. Sin embargo, se le percibe todavía como una cultura marginal.

Cierra el capítulo hablando de los dos premios Nobel que México ha tenido: uno en literatura, con Octavio Paz, y otro en química, con Mario Molina. Sin embargo, notamos que no menciona el premio Nobel de la Paz obtenido por Alfonso García Robles en el año 1982.

El autor trata el tema del narcotráfico, considera que es necesaria la guerra contra éste. También hace un análisis del grave deterioro del medio ambiente que ha sufrido México, y que sólo se le enfrentó en la década de los ochenta del siglo xx. Por último, asegura que la zona más contaminada, además del Distrito Federal, es la de Coatzacoalcos, Veracruz, a pesar de que en 2003 se suprimieron las descargas de aguas residuales que hoy se están llevando a plantas de tratamiento. En suma, hablar del México contemporáneo es plantear la realidad que en todos los aspectos se tiene.

Considero que el libro hace un recorrido interesante a lo largo de la historia de México y se suma a la serie de publicaciones para conmemorar el Bicentenario del inicio de la guerra de Independencia nacional y el Centenario de la Revolución mexicana. En general es una buena síntesis de la evolución de México, es una obra de divulgación que refleja el quehacer histórico de sus autores, quienes han procurado que sus páginas sean amenas y didácticas. No podríamos decir que marca un hito en la investigación, pero sí asegurar que cumple su cometido con creces, al proporcionar, en pocas páginas, una dosis mínima del conocimiento histórico que requiere cualquier mexicano al aclarar aspectos confusos de 
la historia y profundizar en ciertas explicaciones de los fenómenos y acontecimientos del pasado.

\author{
Recibida: 8 de febrero de 2011 . \\ Aceptada: 10 de marzo de 2011. \\ María Teresa Jarquín-Ortega \\ El Colegio Mexiquense, A.C. \\ tjarquin@cmq.edu.mx
}

María Teresa Jarquín-Ortega. Es doctora en historia de América por la Universidad Complutense, de Madrid, y doctora en historia de México por el Colegio de México. Actualmente es profesora-investigadora de tiempo completo del Centro de Estudios Históricos de El Colegio Mexiquense. Es miembro del Sistema Nacional de Investigadores, nivel I. Sus líneas de investigación actual son la historia novohispana y la historia regional del Estado de México. Entre sus publicaciones destacan: "La construcción de la primera iglesia de San Juan Bautista, Metepec" y "Escudo de Armas de Cayetano Jacinto de Sotomayor, primer cura provincial de San Juan Bautista Metepec, siglo Xvin”, en María Teresa JarquínOrtega y Bertha Balestra (coords.), San Juan Bautista de Metepec: vástago de dos culturas, El Colegio Mexiquense-Gobierno del Estado de México, Biblioteca Mexiquense del Bicentenario, Zinacantepec, pp. 79-100 y 101-110 (2010); Los santos del corazón de Metepec. San Isidro Labrador y San Miguel Arcángel, Instituto Mexiquense de Cultura-Gobierno del Estado de México, Biblioteca Mexiquense del Bicentenario-H. Ayuntamiento de Metepec, 2009-2012, Toluca (2010); en coautoría, Historia breve. Estado de México, El Colegio de México-Fondo de Cultura Económica, México (2010). 